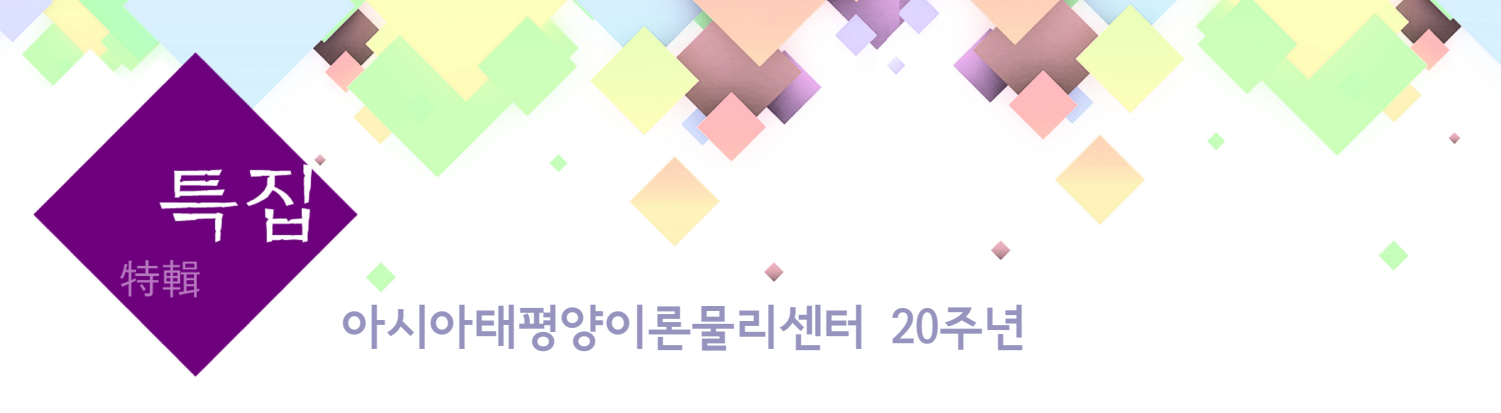

\title{
아태이론물리센터 신진연구그룹(JRG)
}

DOI: 10.3938/PhiT. 25. 057

\section{최 기 영}

Junior Research Group at the APCTP

\section{Ki-Young CHOI}

The Junior Research Group (JRG) is a research program at the Asia Pacific Center for Theoretical Physics (APCTP). The main goal of the JRG is to promote talented young scientists to positions of scientific leadership by offering them the opportunity to qualify for management positions in science. In this article, we summarize the beginning and the progress of the JRG program.

\section{신진연구그룹(JRG)의 개요}

신진연구그룹(Junior Research Group, JRG)은 아시아 태평 양 이론물리센터(APCTP)의 핵심 연구조직이다. JRG는 이론물 리 분야의 신진 연구자를 지원하여 차세대 리더를 배출하는 프로그램이다. JRG의 그룹장은 5 년간의 안정적인 지원 아래 그룹 운영에 관한 독립적 권한을 부여받아 창의적인 연구 활 동을 할 수 있도록 보장받는다.

JRG의 유치는 APCTP의 3, 4대 소장을 역임한 피터 풀데 (Peter Fulde) 소장이 부임하게 되는 2007년부터 시작된다. 풀 데 소장은 임기 시작 전부터 APCTP와 막스플랑크 연구소가 함께 국제 공동 연구 그룹을 운영하여 센터를 세계적인 연구 기관으로 발전시켜 나가겠다는 의지를 가지고 있었으며, 한국 정부와 독일 막스플랑크재단(MPG)이 매칭펀드 형식으로 재원 을 투자하는 방안을 추진하자고 제의하였다.

막스플랑크재단은 1911년 “카이저-빌헬름 학회”라는 이름으

\section{저자약력}

최기영 교수는 2005년 서울대학교 물리학과를 졸업(박사 학위)한 후 영국의 세필드대학교, 스페인의 마드리드 아우토노마 대학교에서 박사후연구원을 지 내고, 부산대학교에서 연구교수를 거친 후 APCTP의 JRG 그룹장으로 활동 하였다. 그 후 천문연구원의 선임연구원을 거쳐 현재 전남대학교 조교수로 근무 중이다.(kiyoungchoi@jnu.ac.kr)
로 시작하였으며, 1918년 노벨물리학상을 수상한 막스 플랑크 의 이름을 따 명칭을 바꾸었다. 물리, 화학, 생물, 의학 등 자 연과학 분야를 비롯하여 경제학과 법학 등 다양한 학문분야에 걸쳐 80 개의 산하 연구소를 가지고 있다. 특히 막스플랑크 $\mathrm{JRG}$ 는 MPG에서 1969년부터 신진연구자들을 지원하기 위하 여 시행하고 있던 차세대 리더 양성 프로그램이다.

막스플랑크재단의 피터 그루스(Peter Gruss) 이사장은 2007 년 10월 5일 포스텍을 방문하여 포스텍 백성기 총장, APCTP 의 피터 풀데 소장과 함께 공동연구협약을 체결하였다. JRG의 리더는 독일 $\mathrm{MPG}$ 의 엄격한 심사기준과 $\mathrm{APCTP}$ 가 정한 절차를 거쳐 엄정하게 선발하게 되며, 그 재원은 독일 막스플랑크 재 단과 APCTP가 공동으로 부담하기로 하게 된다. 또한 포스텍 은 JRG에 연구 및 방문 인프라를 지원하고, 포스텍 학생이 연 구에 참여할 수 있도록 하며, 그룹 소속 연구원이 포스텍 연구 원 신분을 겸직할 수 있도록 하는 등 각종 지원을 하기로 하 였다. 이어서 경상북도와 포항시에서도 추가적인 지원을 하게 된다.

\section{$\mathrm{JRG}$ 의 운영}

$\mathrm{JRG}$ 의 그룹장은 최초 3 년을 계약하고 평가를 통하여 2 년을 연장함으로써 총 5 년의 고용기간을 보장받는다. 포스텍 물리학 과의 겸직교수의 신분으로 학생 지도 및 강의가 가능하고, 연 구에 필요한 제반 요소를 지원받을 수 있다. 또한 안정적인 연 구수행을 위하여 포스텍 내 가족숙소를 제공받으며 조교수급에 준하는 급여와 박사후연구원 1-2명, 대학원생 1-2명 정도의 그룹을 만들 수 있는 연구비를 지원받는다. 무엇보다도 그룹장 은 박사후 연구원, 박사과정 학생들로 자유롭게 그룹을 구성하 며 기획, 조정할 수 있는 운영전반에 대한 독립적인 자율성을 가짐으로써, 그룹장의 창의성을 최대한 발휘할 수 있도록 지원 받는다.

$\mathrm{JRG}$ 의 연구 분야는 센터의 중장기 연구발전방향 및 기존연 구그룹과의 공동연구가능성 등을 고려하여 선정된다. 특히, 이 론물리 분야별로 (응집물질, 천체·우주, 생물·복잡계, 입자) 연 
구그룹을 최종 10 개 그룹까지 구성하여 전문성 및 효율성을 제고할 수 있도록 계획을 하였다.

$\mathrm{JRG}$ 그룹장의 선발은 공고에서 선정과 그룹의 시작까지 1 년에 가까운 기간을 들여 신중하게 이루어진다. 국내외 각종 주요 기관 및 학술 저널, 채용알림 홈페이지에 JRG 모집공고 를 한다. 우수한 인재가 많이 지원할 수 있도록 3 개월 이상의 충분한 공고기간을 가진다. 지원자는 이력서, 연구업적, 선정 후 연구 계획서를 온라인 또는 우편을 통하여 접수하여야 하 며, 특히 관련된 연구 분야의 학자들에게 추천서를 부탁하여 $\mathrm{APCTP}$ 로 직접 보내야 한다.

$\mathrm{JRG}$ 그룹장의 심사는 서류심사, 발표평가, 개별면접 및 최 종선정으로 이루어진다. 서류심사는 APCTP 소장 및 학술코디 네이터 등 분야별 국내전문가로 구성된 사전선발위원회에 의하 여 이루어지며, 자격검증 및 2차 심의 대상자를 선정한다. 발 표 평가와 개별 면접은 소장과 국내외 커뮤니티로부터 추천받 은 세계적 석학 및 연구 분야별 권위자 3 명 이내로 구성된 선 발위원회가 담당하게 된다. 평가의 척도는 연구자의 연구 역량 및 자질, 연구내용의 창의성 및 도전성, JRG 사업과의 부합성, 연구자의 발전가능성 등으로 이루어져 있다. 선발위원회로부터 추천된 후보자에 대하여 소장이 최종심의를 하고 확정을 함으 로써 JRG 그룹장이 선정된다.

선발된 그룹의 연구활동 및 연구실적은 매년 11 월경 과학위 원회의 평가를 받으며, 그 결과에 따라 차년도 연구비 인상여 부도 정해진다. 또한 3 년이 지난 후 중간평가를 통하여 2년 연장여부를 결정하게 된다.

\section{0년 이전의 JRG}

2007년 11월 JRG 그룹장의 첫 번째 공개모집이 이루어졌 으며, 3 개 그룹이 선정되었다. '응집물질물리와 장이론 방법론' (그룹장 신완), '다단계 모델링 및 계산적 접근'(그룹장 신저우), 두 JRG 그룹과 '강하게 상호작용하는 전자계에서 양자 상전이 현상 연구'(연구교수 김기석)이 2008년 6월 출범하게 된다. 처 음 JRG 그룹은 그룹간의 시너지효과를 이루어내고 포스텍 물 리학과와의 공동연구를 염두에 두고서 응집물질분야를 중심으 로 선정되었다.

신완(Xin Wan) 박사가 이끄는 ‘응집물질물리와 장이론 방법 론'(Condensed Matter \& Field Theory Group) 그룹에서는 현대적인 장이론과 수치 계산을 이용하여 이론적인 모형뿐만 아니라 실험적인 시스템에서 나타나는 여러 가지 위상정렬 (topological ordering)을 연구하였다. 또한 비가환 위상을 이용 한 위상양자계산의 가능성도 연구하였다.

신저우(Xin Zhou) 박사를 그룹장으로 한 다단계 모델링 및
계산적 접근'(Multi-scale Modeling Group) 그룹에서는 멀티스 케일 계산과 시뮬레이션 방법을 이용하여 생화학물질(biological macromolecules)의 평형상태와 동적 특성을 연구하였으며, 또 한 여러 가지 공간적, 시간적 척도에서 복잡계를 연구하였다.

김기석 박사의 '강하게 상호작용하는 전자계에서 양자 상전 이 현상 연구'(Quantum Phase Transitions in Strongly Correlated electron Systems) 그룹에서는 장론에 기초하여 비페 르미 액체물리의 본성을 밝히는 연구를 하였다. 게이지 이론 접근 방식을 바탕으로 무거운 페르미 액체계에서 일어나는 자 성 상전이 현상과 초전도 현상, 모트 절연체에서 일어나는 초 전도 현상의 근본 원리를 연구하였다. 강상관 전자계의 비섭동 적인 이해를 위해 최근 10 여 년간 스트링 이론에서 활발하게 연구되고 있는 AdS/CFT 대응성을 양자 상전이 문제에 적용하 고 발전시켰다.

2008년 10월 두 번째 JRG 공개 모집이 끈이론 물리와 응 집물리 분야에 이루어졌다. 그 해 12 월 피터 풀데 소장을 비 롯한 홍콩, 대만, 일본, 중국 등의 위원이 참가한 가운데 과학 위원회에서 그룹장을 선정하게 된다. '강하게 상호작용하는 계 에서 끈이론'(그룹장 김영만)와 '강상관 전자계에서의 협동현상' (그룹장 테츠야 타키모토) 그룹이 2009년 7월 시작하게 된다.

김영만 박사를 그룹장으로 한 강하게 상호작용하는 계에서 끈이론 연구'(String Theory in Strongly Interacting Systems) 그룹에서는 끈이론의 연구방법을 이용하여 강하게 상호작용하 는 계를 연구하였다. 특히, 쿼크-글루온 플라즈마, 중성자별의 핵과 같이 밀도가 높은 $\mathrm{QCD}$ 물질의 상태, 저에너지 하드론 물리, 응집물리계와 같은 강하게 상호작용하는 현상을 연구하 였다. 김영만 박사는 국제공동연구그룹 프로그램 활성화에 기 여하고 세계적 연구 성과 창출을 위해 국제공동연구를 통한 연구역량을 강화한 공로로 2011년 교육과학기술부장관 표창을 수상하게 된다.

테츠야 타키모토(Tetsuya Takimoto) 박사의 '강상관 전자계 에서의 협동현상'(Cooperative Phenomena in Correlated Electron Systems) 그룹은 응집물질물리에서 강상관 전자계에 관한 연구를 하였다. 특히, (1) 반전대칭이 없는 계에서 양자임 계성과 관련 없이 나타날 수 있는 비페르미 액체의 연구 (2) $\mathrm{Li}_{2} \mathrm{Pt}_{3} \mathrm{~B}$ 에서 위상적으로 특별한 상태의 초전도 연구 (3) 반강 자성과 공존하는 초전도 상태에서 스핀 들뜸 (4) $\mathrm{URu}_{2} \mathrm{Si}_{2}$ 에서 숨겨진 질서 등과 같은 연구를 중점적으로 하였다.

\section{0년 이후의 JRG}

2010년에 5월, 첫해에 JRG를 시작하였던 신완과 신저우가 $\mathrm{JRG}$ 를 떠나게 된다. 신완은 절강대학교(Zhejiang University) 
로 돌아가고, 신저우는 중국 과학아카데미(Chinese Academy of Science)의 그룹리더로 제안을 받았다. 그리고 2 개의 새로 운 JRG가 2010년에 시작한다. 겐타로 와타나베의 '초저온 원 자가스'(그룹장 Gentaro Watanabe) 그룹이 5월에, 한노 잘만 의 루프 양자 중력과 작은 규모의 시공 구조'Loop quantum gravity and the small scale structure of space-time) 그룹 이 10 월에 시작하게 된다.

겐타로 와타나베(Gentaro Watanabe) 박사의 '초저온 원자가 스'(Ultracold Atom Gases) 그룹에서는 초저온 원자가스의 양 자 다체 시스템을 다루는 방법과 응용에 관한 이론적인 연구 를 하였다. 특히, 광격자에서 초유체 페르미 가스, 분산을 이용 한 양자상태 가공, 조절된 보즈-허바드 계에서 터널링 효과와 같은 연구를 하였다.

한노 잘만(Hanno Sahlmann)의 루프 양자 중력과 작은 규 모의 시공 구조'Loop quantum gravity and the small scale structure of space-time) 그룹은 고리 양자 중력에서 양자 시 공의 역학을 연구하였다. 또한 양자중력의 배경 하에서 전파해 가는 물질이나 인플레이션 기간 동안에 만들어지는 우주론적 섭동도 연구하였다.

2010년의 신저우 박사에 이어서 2011년에는 JRG의 김기석 박사가 포스텍 물리학과로부터, 한노 잘만 박사는 독일의 에를 랑겐 대학(University Erlangen)으로부터 교수 제안을 받았으 며, 김영만 박사는 기초과학연구원(IBS)으로부터 그룹 리더로 제안을 받았다. 이처럼 JRG 그룹장들이 국내외의 우수 대학과 연구소로부터 제안을 받아 가는 것은 그만큼 JRG가 성공적으 로 진행되고 있다는 것을 보여준다고 할 수 있다.

떠나는 JRG 그룹과 함께, 2011년 중반에 생물물리와 입자, 천체물리 분야에서 3 개의 $\mathrm{JRG}$ 가 새로 시작한다. 조용석 박사 의 '생체연성물질이론'(Biological and Soft Matter Theory) 그 룹이 6월에, 최기영 박사의 ‘입자-천체물리와 우주론'(AstroParticle Physics and Cosmology) 그룹이 7월, 그리고 김판준 박사의 '복잡한 생명계의 창발하는 역학'(Emergent Dynamics of Complex Living Systems) 그룹이 12월에 시작하였다.

조용석 박사의 '생체연성물질이론'(Biological and Soft Matter Theory) 그룹에서는 세포 크기 수준에서 분자의 운동을 지배 하는 생체연성물질의 정전기적, 그리고 동역학적 특성을 이해 하기 위한 연구를 하였다. 이론과 시뮬레이션 방법을 동시에 발전시키면서 생체연성물질의 실험과 이론을 연결시키는 데 공 헌하였다.

최기영 박사의 ‘입자-천체물리와 우주론'Astro-Particle Physics and Cosmology) 그룹에서는 천체물리와 우주론 그리고 입 자물리의 통합적인 관점에서 초기 우주의 진화와 암흑 물질의 정체를 밝히기 위하여 연구를 추진하였다.
김판준 박사의 '생체 복잡계의 창발적 동역학'(Emergent Dynamics of Complex Living Systems) 그룹에서는, 최근에 대량으로 집적되고 있는 생체 데이터를 통계물리학적 기법을 적용하여 대규모로 분석하고 모델링함으로써 생명 현상의 숨어 있는 질서를 해독하고자 한다. 여러 생명 현상 중에서도, 세포 안에서 일어나는 다양한 단백질과 유전자와의 상호작용이 빚어 내는 세포 내(intracellular) 분자 상호작용 네트워크와, 세포와 세포가 다양한 대사물질과 신호전달 물질로 서로 작용하는 세 포 간(intercellular) 분자 상호작용 네트워크의 집단동역학을 연구한다. 예컨대, 세포 내 상호작용 중에서는 생체시계의 리 듬을 생성하는 유전자-단백질 상호작용 네트워크, 세포 간 상 호작용 중에서는 인체 서식 미생물 군집의 대사작용 네트워크 의 집단 동역학에 초점을 맞추고 있다. 셍체시계와 인체서식 미생물 군집은, 인체의 각종 대사작용과 면역작용 등을 관장하 는 중추적 시스템이라는 공통점이 있고, 이 두 시스템이 잘못 되면 각종 대사질환과 면역질환, 암 등을 유발할 수 있다.

2012년 3개의 새로운 JRG가 출범을 한다. 9월에는 조정효 박사의 '세포 네트워크의 디자인 원리'(Design Principle of Cellular Networks) 그룹, 10 월에는 아르만 샤필루 박사의 '물 리우주론'(Physical Cosmology), 그리고 11월에는 공진욱 박사 의 '우주거대구조의 생성과 진화'(Generation and Evolution of Cosmic Structure) 그룹이 시작하였다. 그와 함께 2013년 2 월에는 테츠야 타키모토 박사가 한양대학교의 교수로서 APCTP를 떠나게 되었다.

조정효 박사의 '세포 네트워크의 디자인 원리'(Design Principle of Cellular Networks) 그룹에서는 생체시스템에서 세포들의 동적 상호작용과 공간적인 구조를 계산과학을 통하여 연구한 다. 구체적으로 에너지 항상성 조절을 위한 췌장소도의 세포 네트워크와 안정적이고 유연한 학습을 위한 신경망을 연구하고 있다.

아르만 샤필루 박사의 '물리우주론'Physical Cosmology) 그 룹에서는 천체물리와 우주론의 이론과 관측을 비교하는 데이터 분석에 관한 진보적이고 혁신적인 통계적 방법에 관하여 연구 를 하였다. 우주의 거대구조를 이루는 우주의 초기밀도섭동과 우주의 가속팽창에 관하여 연구를 하였으며, 가장 최신의 우주 론적 관측 데이터를 이용하여, 우주론의 가장 간단한 모형인 바닐라 모형을 검증하는 연구를 수행하였다.

공진욱 박사의 '우주거대구조의 생성과 진화'(Generation and Evolution of Cosmic Structure) 그룹에서는 우주의 거 대구조를 일으키는 밀도 섭동이 인플레이션 동안 생성되는 과 정을 연구하고, 나아가 우주론적 관측을 이용하여 밀도 섭동의 비선형적 진화를 연구하여 우주 진화의 과정을 연구하고 있다. 공진욱 박사는 이론물리학에 큰 기여를 한 공로로 2014년 
한국물리학회에서 백천물리학상 을 수상하였다.

2008년부터 2012년까지 독일의 막스플랑크 재단에서 JRG 를 위하여 매년 30만 유로(5년간 총 150만 유로)를 지원하였 다. 5년간의 지원 기간이 끝나고 2013년부터 JRG 운영은 2 단계 사업(2013년 2017년)에 들어갔다. JRG 예산이 반으로 줄게 되고 정부의 예산이 늘지 않아 2013년에는 JRG를 확장 하는 데 어려움을 가지게 된다.

\section{현재의 JRG}

2014년 예산의 증가로 새로이 2개의 JRG를 시작할 수 있 게 된다. 박명훈 박사의 암흑물질탐색과 입자충돌기 실험에서 새물리의 현상연구'Phenomenology of new physics in Dark Matter Searches and Collider Experiments) 그룹이 11월에 알리레자 아크바리(Alireza Akbari) 박사의 다체 이론과 강상 관 시스템'(Many-Body Theory and Correlated Systems) 그 룹이 12월에 시작한다. 그리고 2014년 12월에는 아르만 샤필 루 박사가 한국천문연구원 선임연구원으로 옮기게 된다.

박명훈 박사의 암흑물질탐색과 입자충돌기 실험에서 새물 리의 현상연구'(Phenomenology of new physics in Dark Matter Searches and Collider Experiments) 그룹에서는 거 대강입자가속기(Large Hadron Collider, LHC)를 이용하여 암 흑 물질을 탐색하고, 제트의 내부구조를 이용하여 $\mathrm{QCD}$ 잡음 을 극복하여 새로운 물리의 신호를 찾는 연구를 수행하였다. 박명훈 박사는 APCTP에서 탁월한 연구의 공로로 2016년 한 국물리학회에서 백천물리학상을 수상하였다. APCTP에서의 연 구 경력을 바탕으로, 박명훈 박사는 2015년 10월에 IBS 순수 물리이론연구단에 선임연구원급으로 옮겼다.

알리레자 아크바리(Alireza Akbari) 박사의 '다체 이론과 강 상관 시스템'(Many-Body Theory and Correlated Systems) 그룹에서는 다체계에서의 그린 함수 방법을 이용하여 강상관계 시스템에서 대칭성이 깨어진 상태들의 동역학을 연구하고 있 다. 밀도행렬과 같은 비평형 방법을 이용하여 펌프-프로브 분 광장치에서 나타나는 초전도와 자성물질의 초고속 동역학을 이 해하고자 한다.

2015-2016년 사이 4개의 JRG 그룹이 새로 시작하였다. 박 찬용 박사의 '게이지/중력 이중성 및 끈이론'(Gauge/gravity duality and string theory) 그룹이 2015년 10월, 조재윤 박 사의 '양자 정보와 다체이론'(Quantum Information and

*백천물리학상: 한국과학상('87), 최고과학기술인상('03), 국가석학('06) 등을 수 상한 김진의 교수(서울대 물리학과)의 호인 '백천'을 따서 제정, 국내 연구자를 격려하는 차원에서 2004년부터 40세 미만의 우수한 국내 이론물리학자에게 수 여함.
Many-Body Theory) 그룹이 같은 해 11월, 에오인 콜게인 (Eoin O Colgain) 박사의 '초중력과 끈이론'(Supergraviry and string theory) 그룹이 역시 2015년 12월에 시작하게 된다. 마지막으로 신창섭 박사의 ‘입자물리와 초기우주’Particle physics and the early Universe) 그룹이 2016년 9월에 연구를 개 시하였다.

박찬용 박사의 '게이지/중력 이중성 및 끈이론'(Gauge/gravity duality and string theory) 그룹에서는 게이지/중력의 이 중성과 그것을 실제적인 물리계에 응용하는 것을 연구한다. 특 히 양자색역학(QCD)이나 응집물질이론처럼 강하게 상호작용하 는 계를 집중적으로 연구하고 있다.

조재윤 박사의 '양자 정보와 다체 이론'(Quantum Information and Many-Body Theory) 그룹에서는 양자 정보이론을 이용하여 강상관계와 같은 양자다체현상을 이해하는 것을 연구 한다. 특히, 양자정보를 이용한 양자상의 연구와 원자/양자 광 학계에서 양자다체이론을 연구하는 것에 중점을 두고 있다.

에오인 콜게인 박사의 '초중력과 끈이론'(Supergraviry and string theory) 그룹에서는 고에너지 입자이론에서 추측하고 있는 초대칭을 통하여 중력과 장이론 사이의 연관관계를 연구 한다.

2015년 겐타로 와타나베 박사는 기초과학연구원을 거쳐 현 재 중국의 저장대학교 물리학과에 있으며, 2016년 조용석 박 사는 기초과학연구원의 연성생체물질센터로 옮겼다. 2016년 8 월까지 11 개 그룹이 거쳐 갔으며, 현재 8 개 그룹이 연구를 수 행 중에 있다.

$\mathrm{JRG}$ 를 통해 이론물리 분야의 젊고 유망한 연구자에게 5 년 이라는 기간 동안 그룹 운영에 관한 독립적 권한을 부여함으 로써, 그룹장은 그룹을 구성하며 기획, 조정할 수 있는 운영전 반에 대한 독립적인 자율성을 확보하고 창의력을 최대한 발휘 할 수 있다. 그 동안 JRG 그룹장으로서 활동하던 연구자들은 모두 탁월한 연구 성과를 보여 학계로부터 많은 관심을 받았 다. 그 결과로 다른 연구기관과 대학으로부터 좋은 자리를 제 안 받아 우수한 연구를 이어갈 수 있었다. 지난 8년간 JRG가 성공적으로 유지될 수 있었던 것도 이러한 취지 아래 믿음을 가지고 $\mathrm{JRG}$ 를 지원해준 $\mathrm{APCTP}$ 의 덕분이라고 할 수 있다. 새 로운 연구 조직으로서 시도된 JRG 프로그램의 가치가 외부에 잘 알려질 필요가 있다. 이를 통해 JRG에 대한 내, 외부적 지 원이 지속, 확대되어 신진연구자들의 창의적인 연구가 계속되 기를 기원한다.

\section{전현직 JRG와 그룹장 목록}

[JRG-1] 'Condensed Matter \& Field Theory Group' (Xin 
Wan, $2008.06 \sim 2010$ )

[JRG-2] 'Multi-scale Modeling Group' (Xin Zhou, 2008.06 $\sim 2010$ )

[JRG-3] 'Quantum Phase Transitions in Strongly Correlated Electron Systems' (김기석, 2008.10 2012.02)

[JRG-4] 'String Theory in Strongly Interacting Systems' (김영만, $2009.03 \sim 2012.08$ )

[JRG-5] 'Cooperative Phenomena in Correlated Electron Systems' (Tetsuya Takimoto, 2009.07 2013.02)

[JRG-6] 'Ultracold Atom Gases' (Gentaro Watanabe, 2010. $05 \sim 2015.04)$

[JRG-7] 'Loop Quantum Gravity and the Small Scale Structure of Space-time' (Hanno Sahlmann, 2010.10 2012.04)

[JRG-8] 'Biological and Soft Matter Theory' (조용석, 2011. $06 \sim 2016.04)$

[JRG-9] 'Astro-Particle Physics and Cosmology' (최기영, 2011.07 2013.12)

[JRG-10] 'Emergent Dynamics of Complex Living Systems' (김판준, 2011.11 현재)
[JRG-11] 'Design Principles of Cellular Networks' (조정효, 2012.9 현재)

[JRG-12] 'Physical Cosmology' (Arman Shafieloo, 2012.9 2014.12)

[JRG-13] 'Generation and Evolution of Cosmic Structure' (공진욱, 2012.11 현재)

[JRG-14] 'Phenomenology of New Physics in Dark Matter Searches and Collider Experiments' (박명훈, 2014.11 2015)

[JRG-15] 'Many-Body Theory and Correlated Systems' (Alireza Akabari, 2014.12 현재)

[JRG-16] 'Gauge/gravity Duality and String Theory' (박찬 용, 2015.10 현재)

[JRG-17] 'Quantum Information and Many-Body Theory' (조재윤, $2015.11 \sim$ 현재)

[JRG-18] 'Supergraviry and String Theory' (Eoin O Colgain, 2015.12 현재)

[JRG-19] 'Particle Physics and the Early Universe' (신창섭, 2016.09 현재) 